\title{
A qualidade atraente percebida em lojas de centros de compras
}

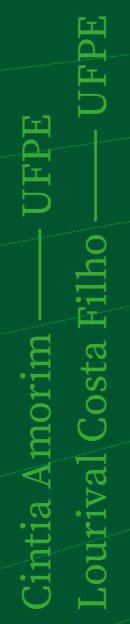


A Indústria de Confecções representa, no contexto nacional, uma das principais atividades econômicas geradoras de emprego $e$ renda (ROCHA, 2002). No Nordeste do Brasil, esse segmento industrial tem grande destaque, principalmente nos setores de comércio e emprego, estando presente em quase todos os estados dessa região, com ênfase nos estados do Ceará, com a capital Fortaleza, e de Pernambuco, com o arranjo produtivo local (APL) de confecções do Agreste, que reúne as cidades de Caruaru, Toritama e Santa Cruz do Capibaribe.

$O$ arranjo produtivo local (APL) de confecções do Agreste de Pernambuco é basicamente composto por micro e pequenas empresas, com produção quase toda voltada para o mercado interno, o que demonstra o caráter social da sua produção, intimamente 
ligada à cultura nordestina. As empresas são, em sua maioria familiares, e os empregos gerados têm grande importância para as localidades que abrangem.

Em termos econômicos, de acordo com informações do SEBRAE (2013), o faturamento anual do APL de confecções do Agreste, como um todo, chegou a 1,1 bilhão em 2011. A principal forma de comércio das mercadorias produzidas nos dois estados do Nordeste aqui enfocados é realizada em centros de compras. Em Fortaleza, no Centro da Moda; em Caruaru, no Polo de Confecções; em Toritama, no Parque das Feiras; e, em Santa Cruz do Capibaribe, no Moda Center Santa Cruz. Os quatro centros têm grandes espaços para o comércio de roupas no varejo e no atacado, distribuídas para todo o país (SEBRAE, 2013). O Moda Center Santa Cruz, por exemplo, é considerado o maior centro atacadista de confecções da América Latina, reunindo mais de 10 mil pontos comerciais.

Levando em conta que cada comerciante tenta chamar atenção para seu ponto comercial através de características distintivas, por apresentar uma imagem desejável e que se destaque das demais nas proximidades, ou seja, que comunique uma qualidade atraente percebida, na medida em que, presumivelmente, uma loja atraente é preferida em relação à outra sem essa característica. Assim, este artigo descreve os principais resultados de uma pesquisa, que teve como objetivo prover informações empíricas sobre a qualidade atraente percebida em cenas de lojas de centros de compras de confecções do Nordeste do Brasil.
A qualidade atraente percebida é uma construção psicológica, pois envolve julgamentos subjetivos. Tais julgamentos consideram referências primárias para os ambientes ou para os sentimentos das pessoas sobre os ambientes avaliados. Os primeiros são chamados de julgamentos perceptuais/cognitivos; enquanto os segundos, de julgamentos afetivos. Como resultado, a qualidade atraente percebida é avaliada nesta pesquisa através de julgamentos afetivos para cenas de lojas de quatro centros de compras de confecções da Região Nordeste do Brasil.

Duas características relacionadas com lojas de centros de compras de confecções coerência e complexidade - foram tomadas para estudo pelas suas prováveis influências na qualidade atraente percebida. A coerência corresponde ao grau em que as cenas se encaixam; enquanto a complexidade é entendida como a quantidade de diferentes elementos na cena.

Os estudos da estética ambiental se justificam para a área da Ergonomia do Ambiente Construído, no sentido de prover recomendações para o desenvolvimento do projeto de lojas e também do design de seus principais elementos, como letreiros e vitrines, em prol das avaliações emocionais favoráveis dos consumidores, pois, segundo Nasar (2000), as características ambientais têm importantes impactos na experiência humana, podendo evocar fortes emoções como prazer ou desprazer, atuar como efeito atraente ou calmante, e possibilitar inferências sobre lugares e pessoas. Podem também influenciar o comportamento humano, de modo 
que as pessoas estão mais propensas a visitar locais que percebem favoravelmente, e a evitar outros que julguem desfavoráveis.

Apesar de as respostas avaliativas, por si só, não poderem prever o comportamento real, a avaliação combinada desse tipo de respostas e do comportamento previsto dá uma boa indicação do comportamento real (NASAR, 2008). Por isso, nesta pesquisa, os participantes foram convidados a indicar em que medida cenas de lojas de centros de compras de confecções com diferentes qualidades visuais atraiam a sua atenção.

\section{ALINHAVOS TEÓRICOS}

A partir deste ponto, este artigo trará alguns postulados teóricos da Estética Ambiental que embasam a avaliação da preferência por lugares (KAPLAN, 1988) e afetiva (RUSSELL, 1988), através de evidências empíricas, com o propósito de apoiar as discussões dos principais resultados.

A Estética Ambiental representa a fusão de duas áreas de pesquisa: a Estética Empírica e a Psicologia Ambiental. Ambas usam metodologias científicas para ajudar a explicar a relação entre os estímulos físicos e a resposta humana. Assim, a principal preocupação da Estética Ambiental abrange o entendimento das influências ambientais sobre a emoção e a tradução desse entendimento em um projeto de ambiente julgado favoravelmente pelo público (NASAR,1988).

Esse tipo de julgamento ambiental, de acordo com Kaplan (1988), é produto de dois propósitos relacionados com a sobrevivência humana: "fazer sentido" e "envolvimento". Um ambiente deve fazer sentido para que se possa atuar nele e ser envolvente para atrair a atenção humana e, à medida que esses dois propósitos são universais para os seres humanos, os ambientes que os apoiam seriam preferidos. Ainda para o autor, a "coerência" é a característica ambiental que está associada ao fazer sentido, enquanto a "complexidade" está relacionada com o envolvimento.

Para o ambiente fazer sentido, deve ser fácil de organizar e de compreender. Ao facilitar a organização e a compreensão, a coerência deve reduzir a incerteza e aumentar o tom hedônico (KAPLAN, 
1988; WOHLWILL, 1976). Essa relação tem sido consistentemente corroborada em pesquisas empíricas (NASAR, 1988).

A complexidade provoca envolvimento. Essa relação, de um lado, vem sendo consistentemente apoiada por achados empíricos para, por exemplo, o tempo de procura e interesse (WOHLWILL, 1976). De outro lado, o tom hedônico (agradabilidade ou beleza), foi postulado como tendo a forma de "U" invertido para a complexidade. $O$ aumento da complexidade eleva o tom hedônico até certo ponto, e depois decai. Assim, baixa complexidade é monótona e entediante; alta é caótica e estressante (WOHLWILL, 1976). 0 nível médio de complexidade parece ser o mais agradável (NASAR, 2000). Os achados empíricos para a complexidade, sob esse enfoque, ainda têm sido inconsistentes, talvez por causa dos procedimentos metodológicos (KAPLAN, 1988; WOLHWILL, 1976). Alguns estudos, conforme Nasar (1988), não conseguiram controlar covariáveis naturais da complexidade; outros não usaram uma gama de complexidade suficiente para desacelerar o tom hedônico.

Embora a qualidade afetiva percebida dependa, em parte, de características perceptuais/cognitivas, ela é, por definição, um julgamento emocional que envolve avaliação e sentimentos dos usuários frente ao ambiente (NASAR, 2008), como deve ocorrer em toda metodologia no âmbito da Ergonomia do Ambiente Construído.

Para ser relevante, esse tipo de julgamento deve focar nas dimensões afetivas que as pessoas realmente utilizam para avaliar um ambiente. Usando uma variedade de estratégias de pesquisa e medidas, Ward e Russel (1981) encontraram quatro dimensões para a avaliação afetiva: agradável, estimulante, atraente e calmante. A agradabilidade é uma dimensão puramente avaliativa. $O$ estímulo independe da dimensão avaliativa. A atratividade e a calma envolvem misturas de avaliação e de estímulo. As pessoas, sob esse prisma, experienciam lugares atraentes como mais agradáveis e estimulantes do que os entediantes/monótonos.

A literatura indica que a coerência (obtida através da redução do contraste entre os elementos da cena) e a complexidade podem influenciar a qualidade atrativa percebida de maneiras previsíveis. A coerência deve reduzir o estímulo (aumentando a atração) e a complexidade deve aumentar o estímulo (elevando a atração). Dessa maneira, a qualidade atrativa percebida deve ser aumentada através da coerência baixa (contraste alto) e da complexidade alta das cenas.

A obtenção da qualidade afetiva percebida depende de diferentes objetivos relacionados às atividades e à função dos lugares, como expõe a Estética Ambiental. Alguns ambientes devem parecer atrativos; outros, calmos. Em suma, o clima emocional do ambiente deve variar para se ajustar aos objetivos da atividade e da função. As lojas, de um modo geral, requerem qualidade atraente.

A partir dos resultados sobre a qualidade afetiva percebida, há possibilidade de estabelecer informações empíricas que possam proporcionar uma boa experiência dos usuários nos ambientes, com direcionamentos 
para que os profissionais das áreas da arquitetura e do design possam desenvolver projetos mais assertivos para lojas, na medida em que a opinião de especialistas se destaca como diferente entre a do público em geral. Sobre o assunto, Nasar (2008) alerta que especialistas em projetos diferem do público com relação às preferências ambientais.

Logo, pesquisar a resposta avaliativa de não especialistas e especialistas em projetos para lojas de centros de compras de confecções, em prol de bases seguras para decisões sobre a qualidade atrativa percebida nesse tipo de espaço, tem importância.

\section{COSTURAS TEÓRICO-METODOLÓGICAS E METODOLÓGICAS}

As relações entre os diversos aspectos da experiência das pessoas com um determinado lugar ou situação podem ser sumarizadas através de uma Sentença Estruturadora (Mapping Sentence), instrumento básico da Teoria das Facetas, criada e desenvolvida por Louis Guttman, que interliga as facetas e resulta em uma frase norteadora para o desenho do instrumento de coleta de dados. Como tal, reflete a hipótese sobre as relações entre os elementos internos das facetas, sendo precisamente essas relações que serão testadas na situação empírica (COSTA FILHO; AMORIM, 2016).

As investigações empíricas nessa linha têm produzido resultados cumulativos que vêm ajudando, paulatinamente, a corroborar ou refutar aspectos dos modelos teóricos de avaliação de lugares (COSTA FILHO, 2014), sem deixar para trás a cognição dos usuários, como sugere a Ergonomia do Ambiente Construído.

O Quadro 1 apresenta a Sentença Estruturadora para a avaliação da qualidade atraente percebida em lojas de centros de compras de confecções, com três diferentes tipos básicos de facetas. O primeiro tipo de faceta se refere ao grupo pesquisado (população amostral). 0 segundo tipo de faceta diz respeito às variáveis a serem pesquisadas/testadas (conteúdo). Juntas, as facetas da população amostral e de conteúdo determinam o campo de interesse da pesquisa (domínio). O terceiro tipo de faceta equivale ao universo das respostas possíveis (racional). 
A partir da Sentença Estruturadora (Quadro 1), os elementos das facetas de conteúdo (contraste e complexidade) podem ser organizados de forma semelhante a uma análise combinatória, produzindo nove diferentes conjuntos ( $\mathrm{A} 3 \times \mathrm{B} 3=\mathrm{AB}$ ), que transmitem uma relação ou situação específica a ser avaliada. Cada uma dessas situações específicas compartilha de um racional, no caso, uma escala ordenada que vai do "nada" (nenhum favorecimento) até "demais" (máximo favorecimento), passando por um estágio intermediário (mais ou menos).

A pessoa $x$ (não especialista - especialista)

avalia que os efeitos das características de

\begin{tabular}{|c|c|c|c|}
\hline FACETA A & & FACETA B & \\
\hline CONTRASTE & \multirow[t]{4}{*}{ e } & COMPLEXIDADE & \multirow{4}{*}{\begin{tabular}{l}
$-1-1$ \\
\hdashline favorecem
\end{tabular}} \\
\hline $\begin{array}{l}\text { (A1) contraste } \\
\text { baixo }\end{array}$ & & $\begin{array}{l}\text { (B1) complexi- } \\
\text { dade mínima }\end{array}$ & \\
\hline $\begin{array}{l}\text { (A2) contraste } \\
\text { médio }\end{array}$ & & $\begin{array}{l}\text { (B2) complexi- } \\
\text { dade moderada }\end{array}$ & \\
\hline $\begin{array}{l}\text { (A3) contraste } \\
\text { alto }\end{array}$ & & $\begin{array}{l}\text { (B3) complexi- } \\
\text { dade máxima }\end{array}$ & \\
\hline \multicolumn{4}{|l|}{ RACIONAL } \\
\hline (1) nada & \multirow{5}{*}{\multicolumn{2}{|c|}{$\begin{array}{l}\text { a qualidade atrativa percebida } \\
\text { em lojas de centros de compras } \\
\text { [resposta avaliativa pretendida] }\end{array}$}} & \\
\hline (2) pouco & & & \\
\hline (3) mais ou menos & & & \\
\hline (4) muito & & & \\
\hline (5) demais & & & \\
\hline
\end{tabular}

Esse conjunto de nove cenas de lojas de centros de compras de confecções está diretamente relacionado com as variáveis da pesquisa (Quadro 2), listadas na Sentença Estruturadora para a avaliação da qualidade atraente percebida em lojas de centros de compras de confecções, levando em conta as duas características ambientais tomadas para estudo - contraste (coerência) e complexidade - em três diferentes níveis.

A Sentença Estruturadora, como uma hipótese inicial da pesquisa, será analisada em relação aos resultados empíricos que devem corroborar ou refutar essa estrutura. Logo, após a interpretação dos dados e na fase final, há informações suficientes para construir ou não uma
Quadro 1

Sentença Estruturadora para a avaliação da qualidade atraente percebida em lojas de centros de compras de confecções. Fonte: Autores da pesquisa, 2020 
nova sentença como consequência direta dos resultados empíricos obtidos (COSTA FILHO, 2014).

A investigação empírica contou com um questionário online, criado por meio da ferramenta "Formulário Google", para coletar os dados com os participantes da pesquisa. $O$ instrumento gerado foi divulgado através da rede social (WhatsApp).

Com relação aos procedimentos de pesquisa adotados, foi informado aos respondentes que: (i) o estudo focava na avaliação visual de lojas de centros de compras de confecções; (ii) não havia resposta certa ou errada; (iii) garantia-se sigilo e anonimato. Em seguida, era pedido que o participante - após a sua caracterização por sexo, idade e escolaridade indicasse em que medida as diferentes cenas de lojas de centro de compras de confecções apresentadas atraiam a sua atenção. 


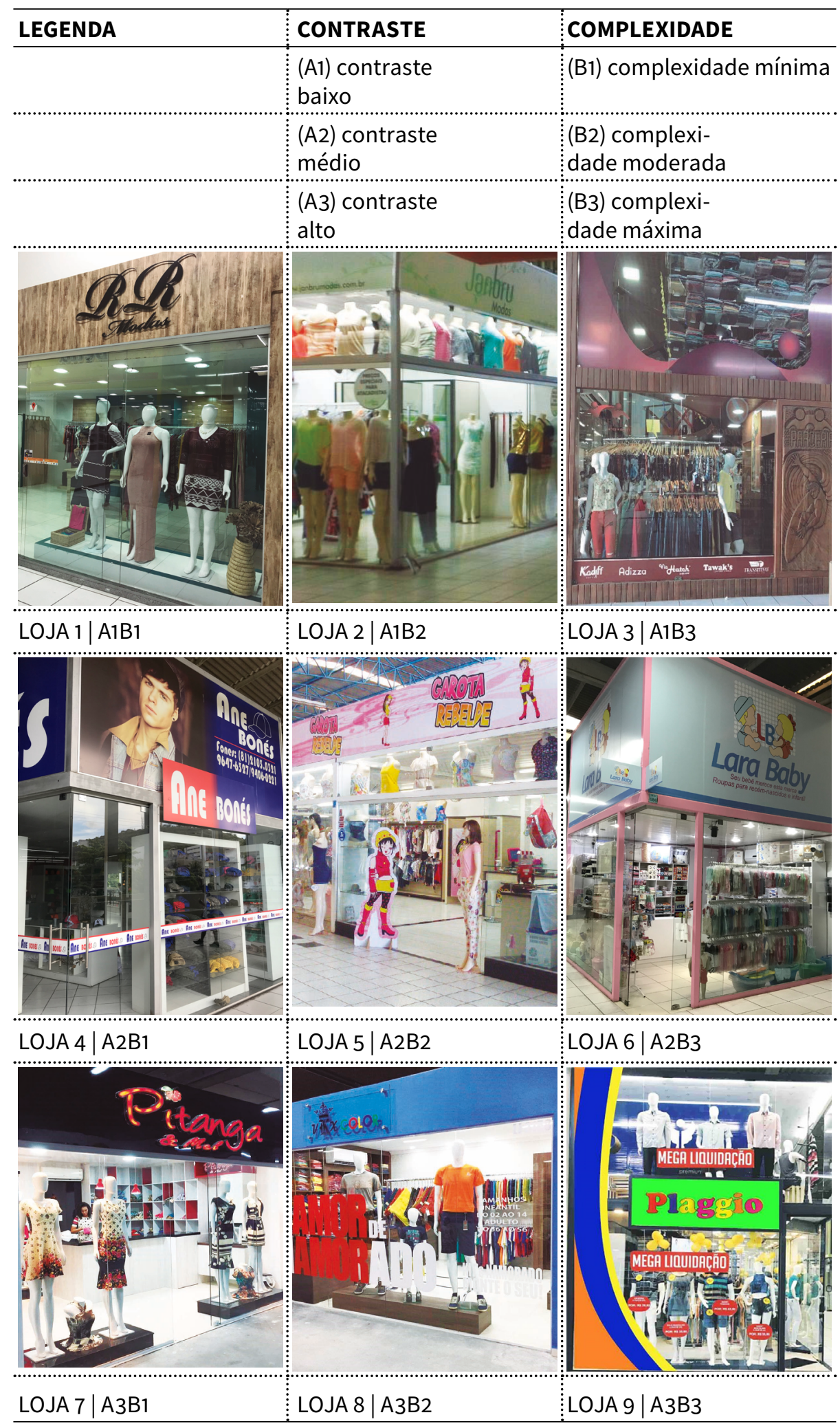

Quadro 2

Cenas de lojas representando as relações entre o contraste e a complexidade Fonte: Autores da pesquisa, 2020 
Ao todo, encerrada a coleta dos dados, contou-se com a participação de 16 pessoas, 8 não especialistas e 8 especialistas em projeto de lojas e do design de seus principais elementos, sendo a maioria mulheres (10) na faixa etária entre 18 e 35 anos, com ensino médio concluído.

A própria ferramenta - utilizada para coletar os dados - realizou o processamento e a arrumação dos dados em um gráfico analítico de barras, que, segundo Marconi e Lakatos (2017), representa as alterações quantitativas proporcionais aos resultados da série respectiva. Cada uma das nove cenas mostra duas barras, que avançam sobre o quadrilátero, com a pontuação atribuída pelos dois diferentes grupos sociais, permitindo verificar as relações que os dados guardam entre si, buscando, ainda: (i) avaliar os efeitos integrados do contraste (coerência) e da complexidade na qualidade atraente percebida nas cenas de lojas de centros de compras de confecções; (ii) identificar as cenas julgadas como mais e menos atraentes pelos dois diferentes grupos abordados; (iii) coligar esses resultados a um determinado nível de contraste (coerência) e de complexidade. 


\section{ARREMATE EMPÍRICO}

O Gráfico 1 representa a qualidade atraente percebida pelos 16 participantes da pesquisa para as nove cenas de lojas de centros de compras de confecções do Nordeste brasileiro. As pontuações, apresentadas separadamente nas duas faixas, equivalem aos escores obtidos por cada uma delas, levando em conta os cinco níveis em que elas favorecem a resposta avaliativa pretendida.

Ao explorar as variações proporcionais do Gráfico 1, pôde-se verificar os efeitos integrados do contraste (coerência) e da complexidade em cenas de lojas de centros de compras de confecções na qualidade atraente percebida, evidenciando as relações entre os elementos internos das duas facetas, estabelecidas na Sentença Estruturadora para a avaliação pretendida.

\section{Gráfico 1}

A qualidade atrativa percebida nas nove cenas de lojas avaliadas. Fonte: Autores da pesquisa, baseando-se nos dados coletados na pesquisa

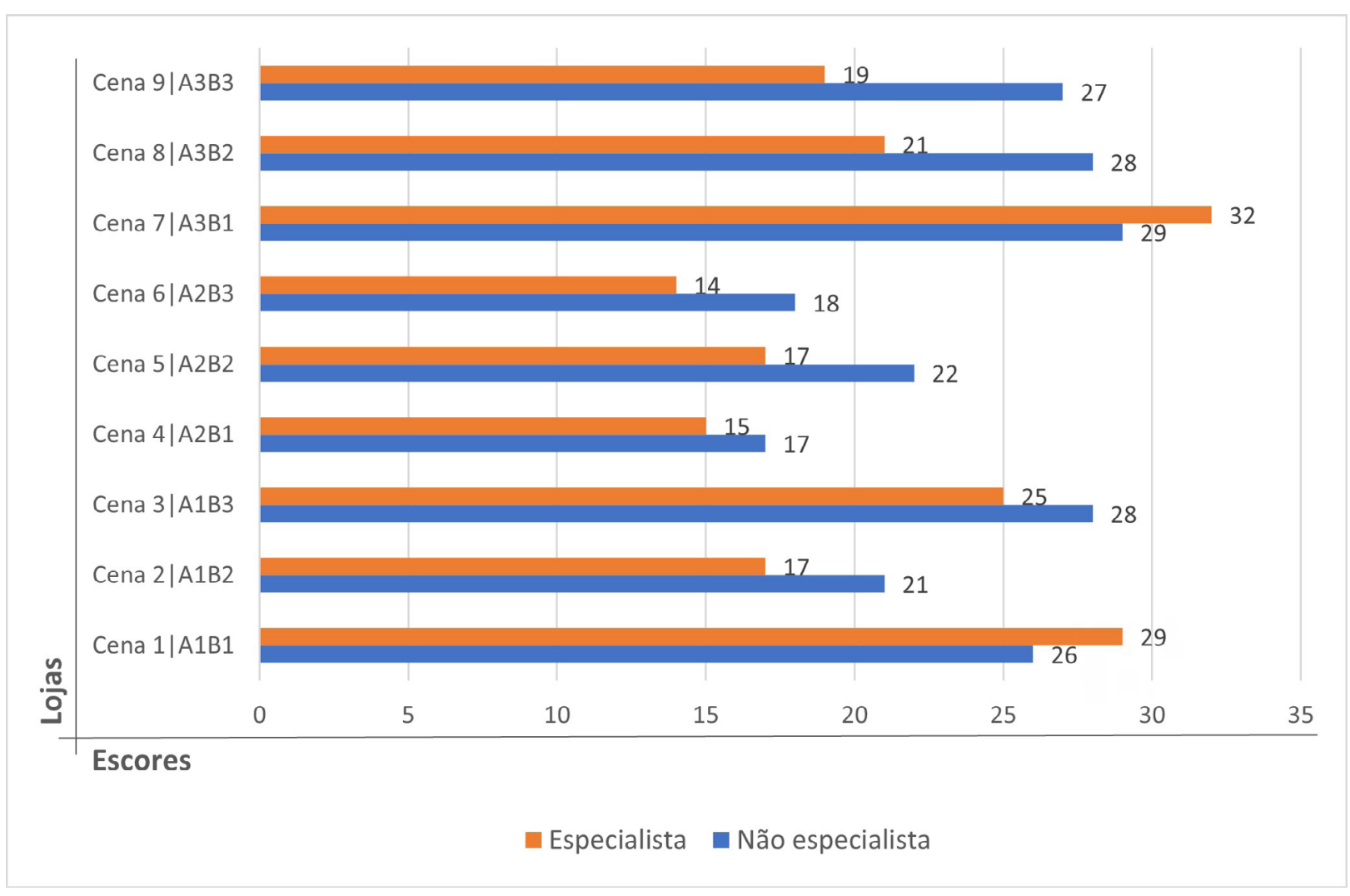


Quadro 3

A qualidade atraente

percebida em cenas de

lojas. Fonte: Autores

da pesquisa, 2020.
Os resultados obtidos, em relação tanto ao grupo de não especialistas, como especialistas em projeto de lojas e design de seus principais elementos, de modo coincidente, revelam parcialmente o efeito sugerido do contraste (coerência) e da complexidade nas respostas avaliativas para a qualidade atraente percebida nas cenas de lojas de centros comerciais de confecções.

A loja 7 (Quadro 2), com contraste alto e complexidade mínima, como mostra o Gráfico 1, foi percebida pelos dois grupos abordados na pesquisa como sendo a mais atraente, ou seja, com maior qualidade atraente percebida. O contraste alto (coerência baixa), conforme detalhado nas considerações teóricas, é sugerido para a qualidade atraente percebida, corroborando com o postulado teórico esperado. Já a complexidade alta, como também referenciado, é sugerida para um lugar atraente, diferente do nível mínimo da cena escolhida como sendo a mais atraente (Quadro 3).

Em relação à cena menos atraente, a loja 4 (Quadro 2), com contraste médio (coerência média) e complexidade baixa, como mostra o Gráfico 1, foi percebida como tal pelo grupo de não especialistas; enquanto a loja 6 (Quadro 2), com contraste médio (coerência média) e complexidade máxima foi considerada como sendo a menos atraente pelo grupo de especialistas, portanto com menor qualidade atraente percebida (Quadro 3).
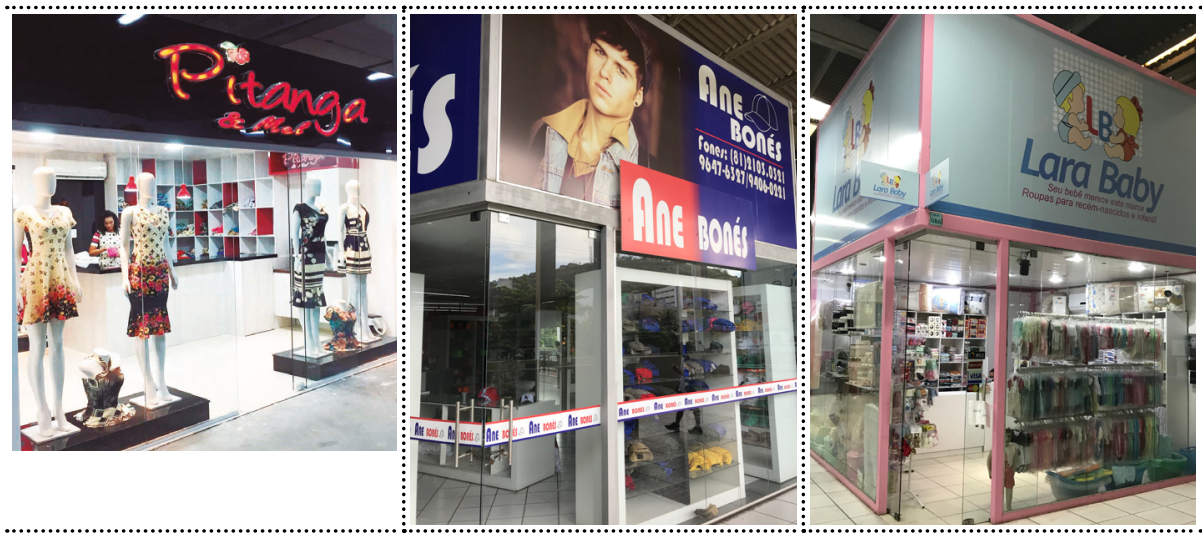

LOJA 7 [A3B1]: cena MAIS atraentes
LOJA 2 [A2B1] e LOJA 6 [A2B3]: cena MENOS atraentes 
A partir do exposto, considerando a percepção dos dois diferentes grupos abordados, é possível afirmar que a qualidade atraente percebida em lojas de centros de compras de confecções é elevada para o contraste alto (coerência baixa), como sugerido para ambientes atraentes; e para a complexidade mínima, resposta avaliativa que destoa do postulado teórico aqui referenciado.

Em um sentido inverso, na percepção do grupo de não especialistas, a qualidade atraente é menor para o contraste médio (coerência média) e complexidade mínima; enquanto para os especialistas seria menor para o contraste médio (coerência média) e complexidade máxima.

Destaca-se, ainda, que a característica do contraste (coerência), no geral, e conforme pode demonstrar o Gráfico 1, parece influenciar mais a elevação da qualidade atraente percebida em lojas de centros de compras de confecções do que a complexidade, isso, evidentemente, a partir da visão dos participantes da pesquisa.

Para finalizar o arremate empírico, como uma consequência direta dos resultados apurados, a Sentença Estruturadora para a avaliação da qualidade atraente percebida em lojas de centros de compras de confecções foi corroborada, ou seja, a manipulação sistemática entre três diferentes níveis das características de contraste e complexidade no tipo de loja escolhido mostrou-se aderente à avaliação proposta.

Assim, os resultados empíricos revelaram que o contraste alto (coerência baixa) e a complexidade mínima elevam as respostas 
avaliativas para a qualidade atraente percebida em cenas de lojas de centros de compras de confecções, sendo menor para o contraste médio (coerência média), na percepção de ambos os grupos, para a complexidade mínima entre os participantes do grupo de não especialistas, e complexidade máxima para os especialistas consultados.

Tais achados sugerem, priorizando a visão dos não especialistas, como recomenda a ergonomia do ambiente construído, que para criar lojas de centros de compras de confecções atraentes, o contraste alto (coerência baixa) e a complexidade mínima devem ser encorajados nos projetos dessas lojas e no design de seus principais elementos, como letreiros e vitrines, e que o número de elementos na cena deve ser controlado. Assim, recomenda-se explorar diferentes cores, texturas, forma e materiais, mas racionalizar a diversidade de elementos na cena.

Esta pesquisa demonstra princípios que governam respostas avaliativas para lojas de centros de compras de confecções. Esses princípios são consistentes com a visão de que a obtenção da qualidade afetiva depende de diferentes objetivos relacionados às atividades e à função dos lugares avaliados, sendo fundamental que os projetistas utilizem referências através de estudos como os discutidos neste documento, para orientar suas decisões projetuais. 


\section{AGRADECIMENTO}

Os autores deste trabalho agradecem à CAPES (Coordenação de Aperfeiçoamento de Pessoal de Nível Superior) pelo apoio recebido, vindo através de uma Bolsa de Mestrado Acadêmico.

\section{REFERÊNCIAS}

COSTA FILHO, L. L.; AMORIM, C. A qualidade avaliativa dos centros de compras do polo de confecções do Agreste de Pernambuco. In: $1^{\circ}$ CONGRESSO INTERNACIONAL DE ERGONOMIA APLICADA [Blucher Engineering Proceedings, v.3 n.3 p. 138146]. São Paulo: Blücher, 2016. ISSN 23577592, DOI 10.5151/engpro-conaerg 2016-7023.

COSTA FILHO, L. L. O enfoque da teoria das facetas na Avaliação de lugares. In: MONT'ALVÃO, C.; VILLAROUCO, V. (Orgs.), Um novo olhar para o projeto, 2: a ergonomia no ambiente construído. Recife: Ed. UFPE, 2014, p. 11-26.

KAPLAN, S. Perception and landscape: conceptions and misconceptions. In: NASAR, J. (Ed.). Environmental aesthetics: theory, research, and application. New York: Cambridge University Press, 1988. p. 45-55.

MARCONI, M. A.; LAKATOS, E. M. 8. ed. [2. Reimpr.]. Técnicas de pesquisa: planejamento e execução de pesquisas, amostragens e técnicas de pesquisas, elaboração, análise e interpretação de dados. São Paulo: Atlas, 2017.

NASAR, J. L. Visual Quality by Design. Holland MI: American Society of Interior Designers, Haworth Inc., 2008. The evaluative image of places. In WALSH, W. B.; CRAIK, K. H.; PRINCE, R. H. 2nd. ed. (Eds.). Personenvironment psychology: new directions 
and perspectives. New Jersey: Lawrence

Erlbaum Associates, 2000. p. 117-168.

. The effect of sign complexity and coherence on the perceived quality of retail scenes. In NASAR, J. L. (Ed.). Environmental Aesthetics: theory, research, \& applications. New York: Cambridge University Press, 1988. p. 300-320.

ROCHA, R. E. V. Proposta de padronização do setor de engenharia para indústria de confecções jeans no estado do Ceará. 54

f. Monografia (Graduação em Engenharia Mecânica) - DEMP/UFC: Fortaleza, 2002.

RUSSELL, J. Affective appraisals of environments. In: NASAR, J. L. (Ed.). Environmental aesthetics: theory, research, and application. New York: Cambridge University Press, 1988. p. 120-129.

SEBRAE-PE. Estudo econômico do Arranjo Produtivo Local do Polo de Confecções do agraste pernambucano, 2012. Publicado: Recife, maio de 2013.

WARD, L.; RUSSELL, J. Cognitive set and the perception of place. Environment and Behaviour, v. 13, n. 5, 1981. p. 219-235.

WOHWILL, J. F. Environmental aesthetics: The environment as a source of affect. In: ALTMANN, I.; WOHWILL, J. F. (Eds.), Human Behaviour and Environment, V. 1, 1976. p 37-86. 